\title{
New strategies to measure intracellular sodium concentrations
}

\author{
Sascha Dietrich ${ }^{a}$, Sarmiza. E. Stanca ${ }^{b}$, Charles G. Cranfield ${ }^{b}$ Birgit Hoffmann $^{b}$, Klaus Benndorf $^{a}$, \\ Christoph Biskup ${ }^{b}$ \\ ${ }^{a}$ University Hospital Jena, Institute of Physiology II, Kollegiengasse 9, 07740 Jena, Germany \\ ${ }^{\mathrm{b}}$ University Hospital Jena, Biomolecular Photonics Group, Nonnenplan 2-4, 07740 Jena, Germany
}

\begin{abstract}
Fluorescent ion indicators are widely used to measure ion concentrations in living cells. However, despite considerable efforts in synthesizing new compounds, no ratiometric sodium indicator is available that can be excited at visible wavelengths. Ratiometric indicators have an advantage in that measured fluorescence intensities can be corrected for fluctuations of the indicator concentration and the illumination intensity, which is not possible when non-ratiometric indicators are used. One way to circumvent this problem is to measure fluorescence lifetimes, which are independent of these factors. Another way to overcome the disadvantages of a non-ratiometric indicator dye is to embed it, together with a reference dye, into nanoparticles. By relating the indicator fluorescence to the fluorescence of the reference dye, inhomogeneities in the nanosensor concentration or the illumination intensity can be cancelled out reliably. In this study we compare the benefits and drawbacks of these approaches.
\end{abstract}

Keywords: sodium measurements, Sodium Green, SBFI, fluorescence lifetime measurements (FLIM), nanoparticles, nanosensors

\section{INTRODUCTION}

In cell physiology sodium plays a crucial role. Mammalian cells maintain a large electrochemical gradient for sodium ions across the plasma membrane. This gradient provides the basis for rapid electrical signaling in many excitable cells. ${ }^{1}$ It also supplies the energy for important secondary active transport processes, in which the sodium influx along the gradient is used to power the co- or counter-transport of other ions or nutrients. ${ }^{2}$ For instance, the $\mathrm{Na}^{+}-\mathrm{H}^{+}$exchanger, and the $\mathrm{Na}^{+}-\mathrm{HCO}_{3}^{-}$co-transporter, help to maintain intracellular $\mathrm{pH}^{3,4} \mathrm{The} \mathrm{Na}^{+} / \mathrm{Ca}^{2+}$ exchanger contributes to the fast restoration of diastolic calcium concentrations in heart cells and also constitutes the dominant calcium efflux pathway in the outer segments of photoreceptor cells. ${ }^{5}$ In epithelial cells of the intestine and the kidney, nutrient uptake (i.e. glucose and amino acids) is powered by a co-transport with sodium. ${ }^{6}$ For an understanding of the molecular action of these membrane proteins, and their role under physiological and pathological processes, it is desirable to know the extra- and intracellular sodium concentration. ${ }^{7}$ Moreover, many sodium dependent carriers and sodium conducting channels are the target of specific drugs. ${ }^{2}$ Knowledge of the actual intra- and extracellular sodium concentration could help to quantify the action of these drugs.

During recent decades, fluorescent indicators have been developed that selectively bind sodium ions and change their absorption and/or emission properties upon binding. These indicators have become a powerful tool in measuring intracellular sodium concentrations $\left(\left[\mathrm{Na}^{+}\right]_{\mathrm{i}}\right)$ in particular, because they provide the possibility to monitor changes of $\left[\mathrm{Na}^{+}\right]_{\mathrm{i}}$ in living cells during the course of an experiment. However, despite considerable efforts in synthesizing new compounds, only a few indicators have been proven to be suitable for measurements in aqueous solutions and biological specimens. Among them, only sodium-binding benzofuran isophthalate (SBFI) and Sodium Green have a $\mathrm{K}_{\mathrm{d}}$ value in aqueous solutions that is close to typical intracellular sodium concentrations. ${ }^{8}$

One important advantage SBFI exhibits over Sodium Green is that changes in $\left[\mathrm{Na}^{+}\right]$do not just cause a change in the fluorescence intensity, but induce also a wavelength shift of the excitation maximum. ${ }^{9}$ Such a shift permits ratioing between signals obtained at two excitation wavelengths. ${ }^{10}$ By calculating the ratio of fluorescence signals elicited by excitation at wavelengths that are shorter (e.g. $340 \mathrm{~nm}$ ) or longer (e.g. $380 \mathrm{~nm}$ ) than the isosbestic point, artifacts that are caused by an inhomogeneous dye distribution inside the cell can be cancelled out. ${ }^{11}$ Because of this property SBFI has been widely used. However, it has a couple of disadvantages due to its short excitation wavelength in the UV-region. First, excitation with UV light can result in considerable photodamage, and second, NADH autofluorescence is also

Multiphoton Microscopy in the Biomedical Sciences X, edited by Ammasi Periasamy, Peter T. C. So, Karsten König, Proc. of SPIE Vol. 7569, 756914 · (c) 2010 SPIE · CCC code: 1605-7422/10/\$18 · doi: 10.1117/12.849742 
excited by UV-light. Therefore the SBFI signal must be separated from cellular autofluorescence, which is not trivial under experimental conditions such as hypoxia and metabolic impairment, where a reliable measurement of the intracellular sodium concentration is of great interest. SBFI can also not be used in most laser scanning microscopes because only few of them are equipped with expensive UV lasers. These disadvantages preclude a wider use of SBFI.

Sodium Green, in contrast, has superior optical properties. First, it can be excited with the $488 \mathrm{~nm}$ line of argon ion lasers, with which most confocal laser scanning microscopes are equipped, and, second, its emission wavelengths are well separated from cellular autofluorescence (Fig. 3). Hence, it can also be used under conditions where cellular autofluorescence is likely to change. Furthermore, Sodium Green has a higher fluorescence quantum yield than SBFI ( 0.2 vs. 0.08$)$, and shows greater selectivity for sodium over potassium (41-fold vs. 18 fold). ${ }^{8}$

However, Sodium Green is not a ratiometric dye. This may result in many artefacts due to an inhomogeneous distribution of the indicator. High fluorescence signals may not only be due to a high sodium concentration, but could also have been caused by an accumulation of the dye. There are no means to disentangle these two effects. Likewise inhomogeneities in the illumination path can bias the fluorescence signal. One way to circumvent these problems is to measure fluorescence lifetimes, which are independent of these factors. Another way is to embed the indicator dye and a reference dye in the polymer matrix of nanoparticles, thereby creating a ratiometric nanosensor. In this study we compare both approaches.

\section{METHODS}

\subsection{Cell culture}

Chinese hamster ovary (CHO) cells were cultured in modified Eagle's Medium (Pan Biotech, Aidenbach, Germany) supplemented with 10\% fetal bovine serum, 1\% L-Glutamine and 1\% penicillin-streptomycin (Invitrogen, Carlsbad, CA, USA). Cells were grown on coverslips and kept in a $5 \% \mathrm{CO} 2$ environment at $37^{\circ} \mathrm{C}$. For nanosensor uptake, cells were washed and resuspended in $960 \mu \mathrm{L}$ of supplement free media, to which $40 \mu \mathrm{L}$ of the nanoparticle dispersion was added. Cells were then kept for $2 \mathrm{~h}$ at $37{ }^{\circ} \mathrm{C}$ in the $5 \% \mathrm{CO} 2$ atmosphere before being repeatedly washed with phosphate buffered saline (PBS). For confocal imaging, cells were transferred to a custom built microscope chamber that enabled perfusion of buffers at room temperature.

\subsection{Spectrofluorometry}

For spectrofluorometry, Sodium Green free acid (Invitrogen, Carlsbad, CA, USA) was added to buffers containing $10 \mathrm{mM}$ HEPES ( $\mathrm{pH}$ 7.4) so that the final indicator concentration was $5 \mu \mathrm{M}$. Sodium chloride concentrations were adjusted as indicated in the respective figures. Sodium chloride was either complemented with tetramethylammonium chloride or potassium chloride to yield a constant ionic strength (e.g. $\left[\mathrm{Na}^{+}\right]+\left[\mathrm{TMA}^{+}\right]=145 \mathrm{mM}$ or $\left[\mathrm{Na}^{+}\right]+\left[\mathrm{K}^{+}\right]=$ $145 \mathrm{mM})$.

All spectrofluorometric measurements were done in a Varian Eclipse fluorescence spectrometer (Varian, Darmstadt, Germany). Fluorescence excitation spectra of Sodium Green and Texas Red were recorded at the emission wavelength $530 \mathrm{~nm}$ and $603 \mathrm{~nm}$, respectively. For measuring the fluorescence emission spectra, Sodium Green and Texas Red were excited at the emission wavelength of the Ar-laser (488 nm) and the He/Ne-laser (543 nm), respectively.

To obtain the dissociation constant $\left(\mathrm{K}_{\mathrm{d}}\right)$ of Sodium Green, fluorescence intensities were normalized and plotted as a function of the free sodium concentration $\left(\left[\mathrm{Na}^{+}\right]\right)$. The data were fitted to the following equation ${ }^{12}$ :

$$
\frac{F}{F_{\text {min }}}=\left(\frac{F_{\max }}{F_{\min }}+\frac{K_{d}}{\left[N a^{+}\right]}\right) /\left(1+\frac{K_{d}}{\left[N a^{+}\right]}\right)
$$

where $\mathrm{F}$ is the fluorescence of the indicator at a given sodium concentration. $\mathrm{F}_{\min }$ is the fluorescence in the absence of sodium, and $\mathrm{F}_{\max }$ is the fluorescence of the sodium-saturated probe. Vice versa, the free sodium concentration ([Na $\left.{ }^{+}\right]$) can be calculated when $\mathrm{K}_{\mathrm{d}}$ is known, using ${ }^{12}$ :

$$
\left[N a^{+}\right]=K_{d} \frac{F-F_{\min }}{F_{\text {max }}-F}
$$




\subsection{Confocal microscopy}

Confocal imaging was performed with a Zeiss laser-scanning microscope (LSM 510 and LSM710, Carl Zeiss, Göttingen, Germany) using a Zeiss C-Apochromat 63x (NA 1.20) water immersion objective. Sodium Green and Texas Red were excited with the $\mathrm{Ar}^{+}$-laser $488 \mathrm{~nm}$ line and the He/Ne-laser $543 \mathrm{~nm}$ line, respectively. Fluorescence was recorded with a 505-550 nm band pass filter (Sodium Green) and a $560 \mathrm{~nm}$ long pass filter (Texas Red).

After loading the cells with the nanosensors and recording the fluorescence intensity under physiological conditions, strophanthidin (10 $\mu \mathrm{M}$, Sigma, St.Louis, MO, USA) and the ionophores gramicidin D (10 $\mu \mathrm{M}$, Sigma), nigericin (5 $\mu \mathrm{M}$, Sigma) and monensin $(15 \mu \mathrm{M}$, Sigma) were added to the extracellular solution to equilibrate sodium across the plasma membrane. By washing in HEPES buffered solutions $(\mathrm{pH}=7.4)$ of varying sodium concentrations the intracellular sodium concentration could be clamped to the desired concentrations. The potassium chloride concentration in the bath solution was adjusted to maintain a constant osmolarity (e.g. $\left[\mathrm{Na}^{+}\right]+\left[\mathrm{K}^{+}\right]=145 \mathrm{mM}$ ).

\subsection{Fluorescence lifetime measurements}

The setup used for time-domain fluorescence lifetime measurements is shown in Figure 1. Samples were scanned on the stage of the confocal laser-scanning microscope (LSM510, Zeiss, Jena, Germany) and excited by ultrashort (FWHM $130 \mathrm{fs})$ light pulses generated by a combination of a $5 \mathrm{~W}$, frequency-doubled $\mathrm{Nd}: \mathrm{YVO}_{4}$ laser $(5 \mathrm{~W}$ Verdi, Coherent, Dieburg, Germany) and a mode-locked Titanium:Sapphire laser (Mira 900, Coherent). A pulse picker (Model 9200, Coherent) was used to decrease the excitation pulse frequency to the fastest possible repetition rate (2 MHz) of the streak camera sweep unit. For two-photon excitation the beam was directly coupled into the IR-port of the microscope. For one-photon excitation the second harmonic of the fundamental laser frequency was generated in a non-linear $\beta$-barium borate (BBO) or a lithium triborate (LBO) crystal. Flippable mirrors (NewFocus, SanJose, USA) were used to switch between the respective excitation paths.

The emitted light was guided via an optical fiber to a polychromator (250is, Chromex Inc., Alburquerque, NM, USA), which spread the incident light along the horizontal axis and focused it on the entrance slit of the streak camera (C5680 with M5677 sweep unit, Hamamatsu Photonics, Herrsching, Germany).

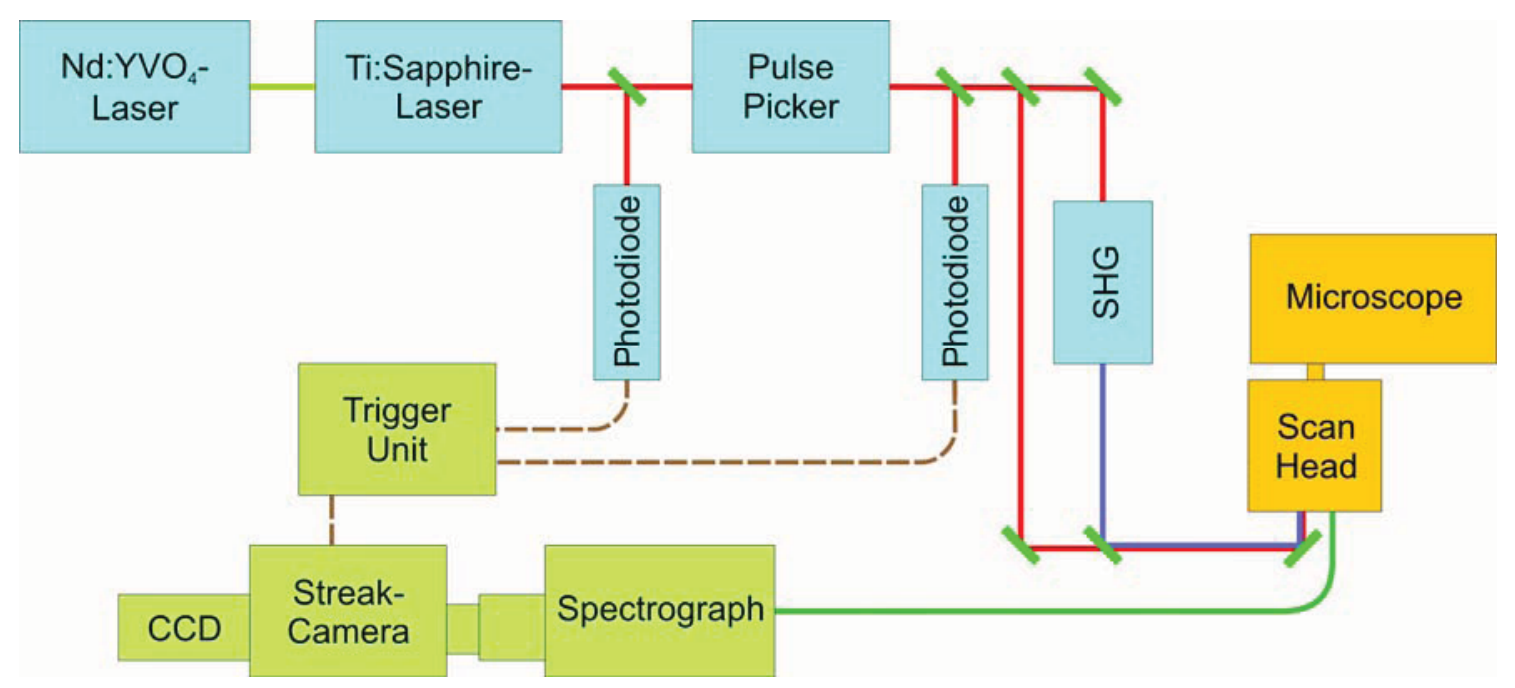

Figure 1.Setup for spectrally resolved fluorescence lifetime measurements. The sample is excited by ultrashort (130 fs FWHM) light pulses generated by a combination of a mode-locked Titanium:Sapphire laser, a pulse picker, and a SHG crystal. Emitted fluorescence is guided through an optical glass fiber to a polychromator, which disperses the fluorescence light according to its wavelength along the horizontal axis and focuses it the entrance slit of the streak camera. 


\subsection{Operation principle of a streak camera}

Figure 2 illustrates the operation principle of a streak camera. The light pulse, which has been horizontally dispersed by the polychromator, is focused onto the photocathode of the streak tube where photons are 'converted' into photoelectrons. The photoelectrons are accelerated by the accelerating electrode, pass through a pair of deflection plates, are multiplied in a micro-channel plate (MCP), and hit the phosphor screen of the streak tube, where they are reconverted into an optical image - the so-called streak image. At the instant the photoelectrons pass through the deflection electrodes a voltage ramp is applied so that the electrons are swept from top to bottom. Electrons leaving the photocathode at earlier times arrive at the phosphor screen in a position close to the top of the screen, while those electrons that leave the photocathode at later times arrive at a position closer to the bottom of the screen. Hence, the time at which the photoelectrons left the photocathode can be determined by their vertical position in the streak image. The horizontal position of the incident photon depends on its wavelength, because a spectrograph was used to focus the spectrum onto the streak-camera entrance slit. Thus the resulting streak image contains information about the temporal distribution of the incident light as a function of its wavelength.

The streak images are read out by a CCD camera and transferred in $111 \mathrm{~ms}$ intervals to a computer. In the so-called "photon counting" mode, a threshold value is used with the streak image to separate out noise. Only signals exceeding the threshold value are counted as one single photon event. The events are added up in the computer memory, and as a result, integrated photon-counting streak images are obtained. If the integration time is long enough a very high signalto-noise ratio can be achieved. The streak images can be used to extract both the fluorescence spectrum and the fluorescence decay curve at the same time. Spectra are generated by summarizing fluorescence intensities along the vertical (time) axis and plotting the resulting intensities versus the horizontal (wavelength) axis. Alternatively, by summing up the fluorescence intensities in the wavelength bands of interest, and plotting the resulting intensities versus the vertical axis, one can obtain fluorescence decay curves. ${ }^{13,14}$

Recorded streak images were analyzed with our own software, which was developed by using MATLab (MathWorks, Natick, USA). From these streak images fluorescence spectra and fluorescence decays were extracted. Fluorescence decays were evaluated using the 'iterative reconvolution method' and a modified Gauss-Newton algorithm to approximate the parameters of a given model. The goodness of the fit was judged by the value of the reduced $\chi_{v}^{2}$.

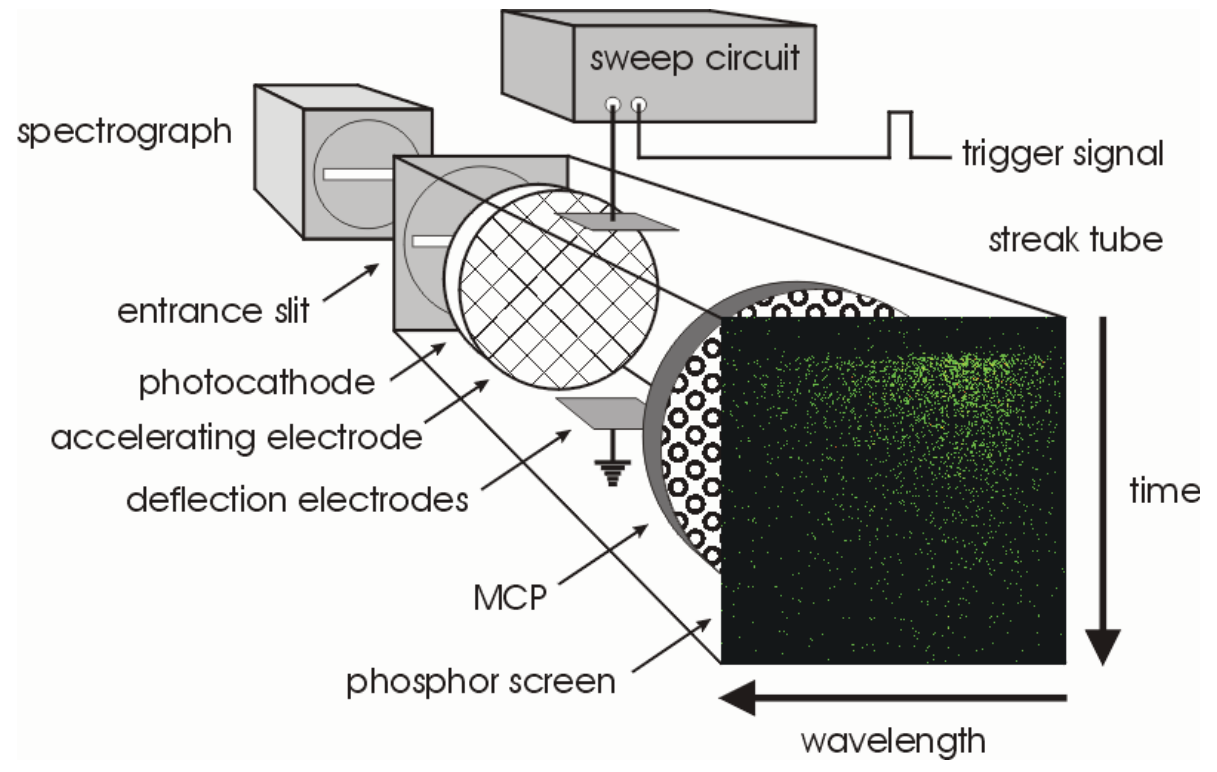

Figure 2. Operating principle of a streak camera (see text for details) 


\subsection{Preparation of Gold Core Polyacetal Coated Nanoparticles}

A detailed description of the synthesis of the nanosensors is given by Stanca et al. ${ }^{15}$ In brief, to create a gold nanoparticle suspension two solutions were made; a gold salt solution containing $1 \mathrm{ml}$ of $1 \% \mathrm{HAuCl}_{4}$ in $79 \mathrm{ml}$ distilled water, and a reducing mixture consisting of $5 \mathrm{ml}$ of $1 \%$ tannic acid in $15 \mathrm{ml}$ distilled water. At $60{ }^{\circ} \mathrm{C}$ the reducing mixture, $100 \mu \mathrm{l}$ of $1 \% \mathrm{PVA}$, and $100 \mu \mathrm{l}$ of $8 \mu \mathrm{M}$ cysteine solution were added to the gold salt solution in quick succession whilst stirring continuously. After completion of the reaction, which was evident from the red colour, the suspension was immediately used for sensor preparation. To attach the indicator dye and the reference dye to the gold core, $10 \mu \mathrm{L}$ of a $10 \mu \mathrm{M}$ solution of the respective fluorophores were mixed with $990 \mu \mathrm{l}$ of the gold suspension whilst stirring for $2 \mathrm{~h}$ at $60{ }^{\circ} \mathrm{C}$. Separately, $18 \mathrm{mg}$ of polyacetal was dispersed in $10 \mathrm{~mL}$ dimethylformamide (DMF) by heating to $135^{\circ} \mathrm{C} .1 \mathrm{ml}$ from this mixture was then diluted with $9 \mathrm{~mL}$ of DMF, cooled to room temperature, and then $10 \mu 1$ of that dispersion was added to $1 \mathrm{ml}$ of the now fluorophore linked nanoparticle dispersion and stirred for $2 \mathrm{~h}$. The gold nanoparticle dispersions were then precipitated with $\mathrm{NaCl}$, centrifuged, and the pellet was dispersed in water to make a $1 \mathrm{ml}$ volume. Immediately prior to use a $40 \mu \mathrm{l}$ aliquot of the above dispersion was diluted with $960 \mu \mathrm{l}$ cell culture medium and added to the cells.

\section{RESULTS}

\subsection{Properties of free Sodium Green}

Figure 3 summarizes some of the chemical and physical properties of the free Sodium Green indicator. In aqueous solution its excitation maximum exhibits a peak at $505 \mathrm{~nm}$, and its emission spectrum has a maximum at $533 \mathrm{~nm}$ (Fig. 3A). Upon binding to sodium ions, Sodium Green exhibits an increase in fluorescence intensity with little shift towards longer wavelengths (Fig 3B). Figure $3 \mathrm{C}$ shows the relative fluorescence $\left(\mathrm{F} / \mathrm{F}_{\mathrm{min}}\right)$ as a function of $\left[\mathrm{Na}^{+}\right]$. The data can be fitted to Eq. 1 (see Methods) yielding a value of $8.6 \mathrm{mM}$ for Sodium Green's dissociation constant $\left(\mathrm{K}_{\mathrm{d}}\right)$. In solutions containing both sodium and potassium (with a total cation concentration of $145 \mathrm{mM}$ ) the $\mathrm{K}_{\mathrm{d}}$ is slightly elevated to a value of $22.4 \mathrm{mM}$ (Fig. 3C). This finding is consistent with a model in which the bigger potassium ion blocks the sodium binding site of the crown ether. Because both $\mathrm{K}_{\mathrm{d}}$ values match the range of intracellular sodium concentrations, physiological changes in $\left[\mathrm{Na}^{+}\right]_{\mathrm{i}}$ are able to exert an effect on the ratio of free to sodium-bound indicator molecules and the overall fluorescence intensity.

By knowing these data it is, in principle, possible to determine $\left[\mathrm{Na}^{+}\right]$in a biological sample. However as Sodium Green is not a ratiometric dye there is no way to correct for inhomogeneities in the distribution of the indicator. High fluorescence signals may not only be due to a high sodium concentration, but could also have been caused by dye accumulation in localised regions of a cell. Likewise inhomogeneities in the illumination path can bias the fluorescence signal.

A

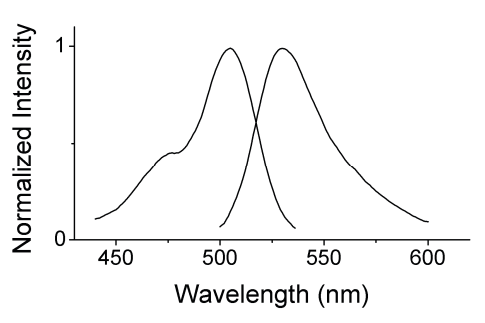

B

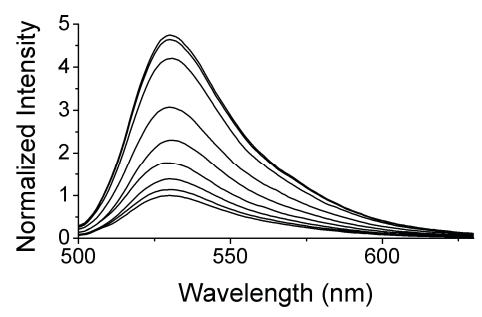

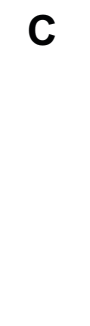

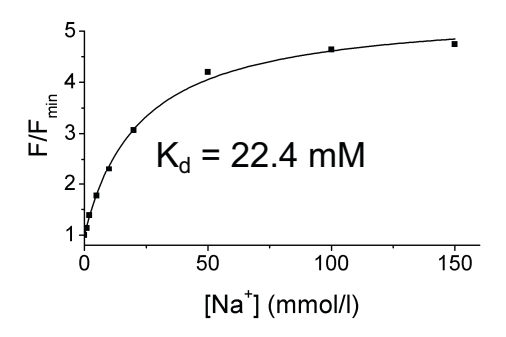

Figure 3. Optical and chemical properties of free Sodium Green. (A) Fluorescence excitation $\left(\lambda_{\text {em }}=530 \mathrm{~nm}\right)$ and fluorescence emission spectrum $\left(\lambda_{\mathrm{ex}}=505 \mathrm{~nm}\right)$ of Sodium Green in buffered solution ( $\left.\mathrm{pH} 7.4\right)$ containing 0 mM sodium. (B) Fluorescence emission spectra of Sodium Green $\left(\lambda_{\mathrm{ex}}=488 \mathrm{~nm}\right.$ ) at sodium chloride concentrations of 0 (bottom), 1, 2, 5, $10,20,50,100$ and $150 \mathrm{mM}$ (top). For all solutions containing less then $145 \mathrm{mM}$ sodium chloride, potassium chloride was added so that the total cation concentration was $145 \mathrm{mM}$. Spectra were normalized with respect to the peak of the emission spectrum at a sodium concentration of $0 \mathrm{mM}$. (C) Fluorescence intensity as a function of free sodium concentration. The data were derived from the emission spectra shown in panel B and fitted to equation 1 (see Methods). The fit yielded a $\mathrm{K}_{\mathrm{d}}$ of $22.4 \mathrm{mM}$. 


\subsection{Fluorescence lifetime measurements of Sodium Green}

Fluorescence lifetimes are independent of the above mentioned factors. They are a property of the fluorophore and its environment. Since sodium binds to Sodium Green, one should expect that it has some effect on the excited state lifetime. If one fluorescence lifetime component can be attributed to the sodium-free form of the dye, and one component to the sodium-bound form, then the overall fluorescence decay should exhibit a biexponential time course (Fig. 4).

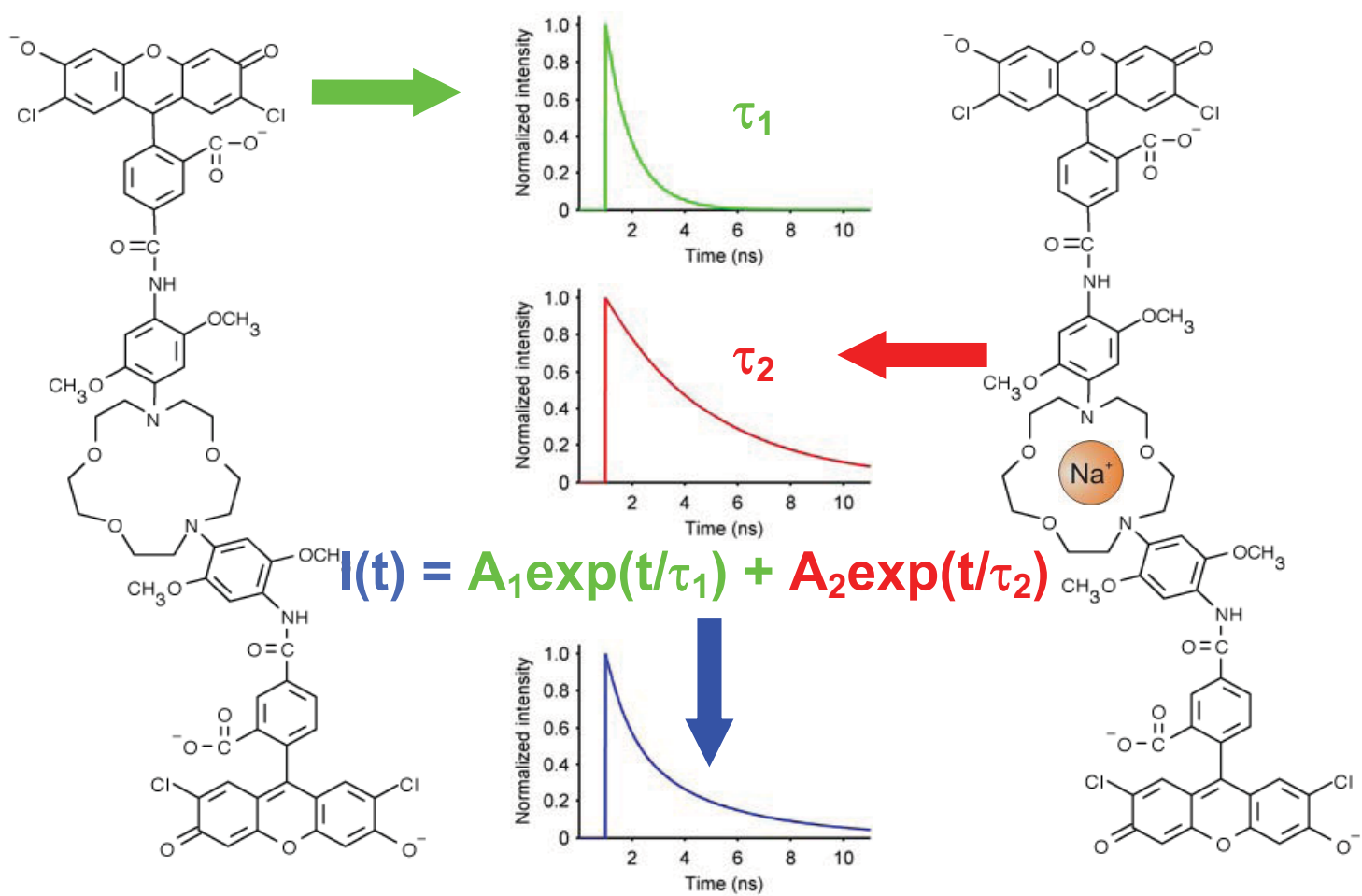

Figure 4. The concept behind fluorescence lifetime measurements. In the ideal case, a fluorescence lifetime component, $\tau_{1}$, can be attributed to the sodium-free form of Sodium Green; and another component, $\tau_{2}$, can be attributed to the sodiumbound form, so that the overall fluorescence decay exhibits a biexponential time course. By fitting a biexponential function to the fluorescence decay, the lifetime components $\tau_{1}$ and $\tau_{2}$, as well as the amplitudes $\mathrm{A}_{1}$ and $\mathrm{A}_{2}$, can be recovered. Provided that this simple model holds and that the fit is appropriate, then $A_{1}$ and $A_{2}$ would be equal to the fraction of the sodium-free and the sodium-bound form of Sodium Green.

Figure 5 shows a series of fluorescence decay measurements obtained with our streak camera system. The fit with a biexponetial model, however, did not yield acceptable results. The fitted curves deviated considerably from the measured intensity decays (Fig. 5A), and the residuals were not randomly distributed (Fig. 5B). The parameters recovered by the fit are shown in Table 1. A triexponential fit could describe the fluorescence decay better (Fig. 5 C,D, Table 1). Similar results were already obtained by measurements in the frequency domain by Szmacinski and Lakowicz ${ }^{15}$ and Despa et al. ${ }^{17}$ Apparently, the fluorescence decay cannot be explained by such a simple model as the one presented in Figure 4, and most likely both forms, the sodium-free and the sodium-bound, exist in several conformational states, with different lifetimes contributing to the overall fluorescence decay. 
A

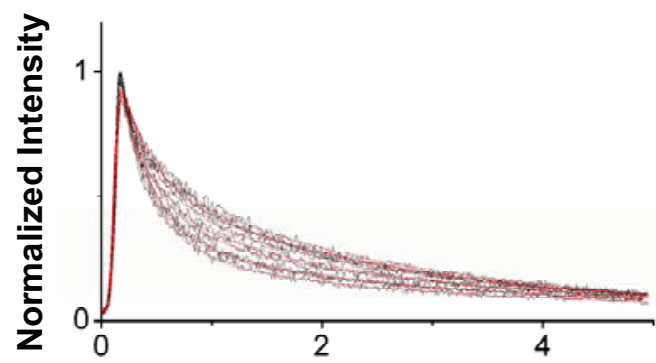

B

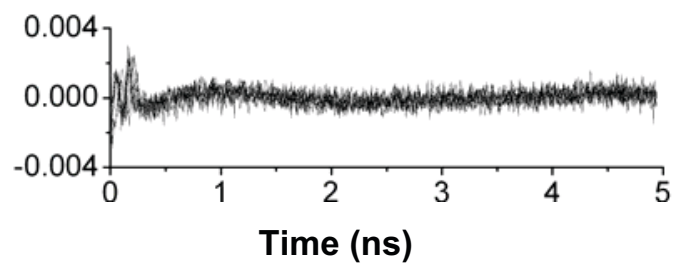

C

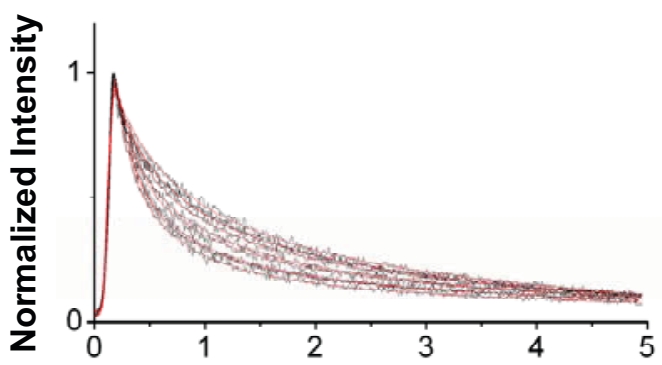

D

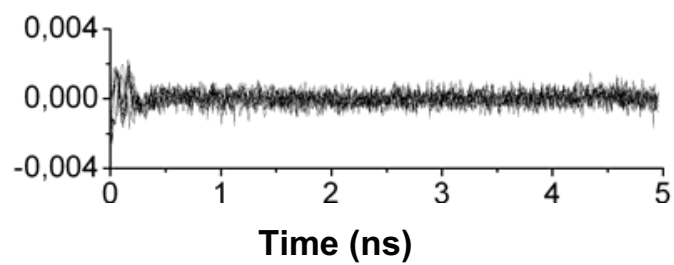

Figure 5. Global fit of fluorescence intensity decays of Sodium Green recorded at varying sodium concentrations ranging from $0,1,2,5,10,20,50$ to $100 \mathrm{mM}$. Sodium chloride was complemented with tetramethylammonium chloride to yield a constant ionic strength of $290 \mathrm{mM}$ (e.g. $\left.\left[\mathrm{Na}^{+}\right]+\left[\mathrm{TMA}^{+}\right]=145 \mathrm{mM}, \mathrm{pH}=7.4\right)$. A) Fluorescence intensity decays (black) and results of the biexponential fit (red). B) Residuals C) Fluorescence intensity decays (black) and results of the triexponential fit (red). D) Residuals. The parameters recovered by the fit are shown in Table 1.

Table 1. Global fit of the fluorescence intensity decays shown in Figure 5. The biexponential fit yielded the global lifetimes of $\tau_{1}=0.30 \mathrm{~ns}$ and $\tau_{2}=2.44 \mathrm{~ns}$. The triexponential fit yielded the global lifetimes of $\tau_{1}=0.13 \mathrm{~ns}, \tau_{2}=0.54 \mathrm{~ns}$ and $\tau_{3}=2.80 \mathrm{~ns}$.

\begin{tabular}{|c|c|c|c|c|c|c|c|c|c|}
\hline & \multicolumn{4}{|c|}{ Biexponential fit } & \multicolumn{5}{|c|}{ Triexponential fit } \\
\hline $\begin{array}{c}\mathrm{C} \\
(\mathrm{mmol} / \mathrm{l})\end{array}$ & $\begin{array}{c}\mathrm{A}_{1} \\
(\%)\end{array}$ & $\begin{array}{c}\mathrm{A}_{2} \\
(\%)\end{array}$ & $\begin{array}{c}\tau_{m} \\
(\mathrm{~ns})\end{array}$ & $\chi^{2}$ & $\begin{array}{l}A_{1} \\
(\%)\end{array}$ & $\begin{array}{c}\mathrm{A}_{2} \\
(\%)\end{array}$ & $\begin{array}{c}\mathrm{A}_{3} \\
(\%)\end{array}$ & $\begin{array}{c}\tau_{m} \\
(\mathrm{~ns})\end{array}$ & $\chi^{2}$ \\
\hline 0 & 75.4 & 24.6 & 0.83 & 1.81 & 46.8 & 36.5 & 16.7 & 0.73 & 1.42 \\
\hline 1 & 72.5 & 27.5 & 0.89 & 1.84 & 47.1 & 33.6 & 19.4 & 0.78 & 1.54 \\
\hline 2 & 69.9 & 30.1 & 0.94 & 2.06 & 43.2 & 35.0 & 21.7 & 0.85 & 1.79 \\
\hline 5 & 64.2 & 35.8 & 1.07 & 1.92 & 38.0 & 35.2 & 26.9 & 0.99 & 1.63 \\
\hline 10 & 59.4 & 40.6 & 1.17 & 1.42 & 31.2 & 37.2 & 31.5 & 1.12 & 1.08 \\
\hline 20 & 54.4 & 45.6 & 1.28 & 1.32 & 26.6 & 37.0 & 36.4 & 1.25 & 1.03 \\
\hline 50 & 48.3 & 51.7 & 1.41 & 1.31 & 18.9 & 38.4 & 42.7 & 1.43 & 1.06 \\
\hline 100 & 47.8 & 52.2 & 1.42 & 1.37 & 16.1 & 40.2 & 43.8 & 1.46 & 1.07 \\
\hline
\end{tabular}

In the presence of potassium ions, more complicated decay models are necessary. ${ }^{15}$ In principle, the average lifetime $\left(\tau_{\mathrm{m}}\right)$ or the amplitudes $\left(\mathrm{A}_{1}, \mathrm{~A}_{3}\right)$ of the fast and slow lifetime component $\left(\tau_{1}, \tau_{3}\right)$ could be still be used to estimate the sodium concentration, despite the lack of a good model. But, in practice, these measurements are biased by interactions of the dye with intracellular components, which makes an analysis of the fluorescence decay impossible.

\subsection{Sodium nanosensors}

For the researcher it would be desirable to have an indicator that has some of the optical properties of Sodium Green, but is not influenced by intracellular proteins. Furthermore, this indicator should permit ratiometric measurements favorably between two emission wavelengths. Unfortunately, such an indicator has never been synthesized despite considerable effort. The need to synthesize such an indicator, however, can be circumvented by incorporating known indicators into a nanoparticle structure that can be tailored to the specific task. In this way it is possible to exploit the analyte recognition capabilities of the indicator and to protect it from the effects of the intracellular environment.

We tried to accomplish this aim by incorporating Sodium Green into nanoparticles consisting of a gold core stabilized by poly(vinyl alcohol) and surrounded by a polyacetal shell (Fig. 6) 


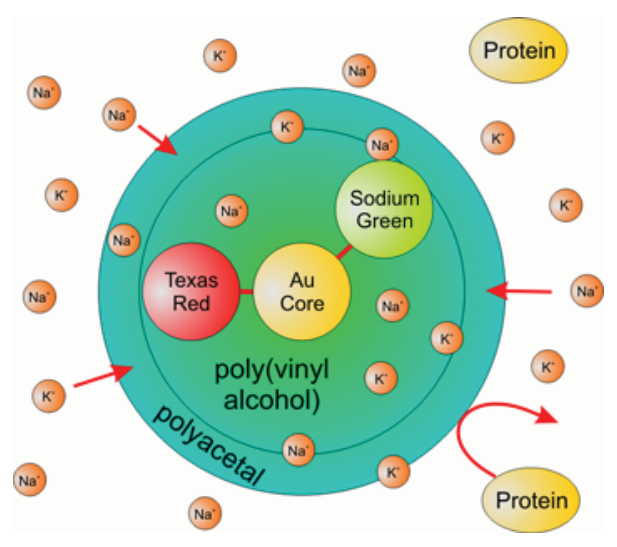

Figure 6. Scheme of the nanosensor architecture. Sodium Green and Texas Red were anchored to the Au core of the nanoparticles via a linker. The particles are stabilized by poly(vinyl alcohol) and surrounded in a polyacetal coating that is permeable to the analyte.

One advantage of this approach is that a second dye can be readily incorporated in the polymer matrix, whose fluorescence signal can then serve as a reference to indicate the nanosensor concentration. Since the reference dye does not need to be attached covalently to the indicator dye, it must meet only two requirements. First, its fluorescence signal must be insensitive to sodium, and second, its fluorescence emission spectrum should be well separated from the indicator dye. In this study Texas Red was used as reference dye. Figure 7A shows the emission spectra of the nanosenors obtained in solutions of different sodium concentrations. The emission intensity of Sodium Green changes as a result of varying sodium concentrations. The slight visible change of the Texas Red fluorescence intensity is caused by the small overlay of Sodium Green's emission spectra.

To test if the nanosensors can be delivered to the cytosol and used for intracellular sodium measurements, we incubated $\mathrm{CHO}$ cells with them. After an incubation period of 2 hours the nanoparticles were readily transferred into the cells without the use of transfection agents. After washing the cells with phosphate buffered saline (PBS) we did not see any evidence that nanoparticles adhered to the plasma membrane. To test the response of the nanosensors, the CHO cells were incubated with ouabain, an inhibitor of the $\mathrm{Na}^{+} / \mathrm{K}^{+}$-ATPase, and the ionophores nigericin, monensin and gramicidin. Fluorescence intensities were then measured in HEPES buffer containing $\mathrm{NaCl}$ concentrations of either 10 $\mathrm{mM}$ or $100 \mathrm{mM}$. Figure 7B shows the time course of the Sodium Green and Texas Red fluorescence signal during the entire experiment. As demonstrated by Figure 7B, switches to and from equivalent sodium concentrations produce repeatedly identical fluorescence signals, even in experiments of over 15 min duration.
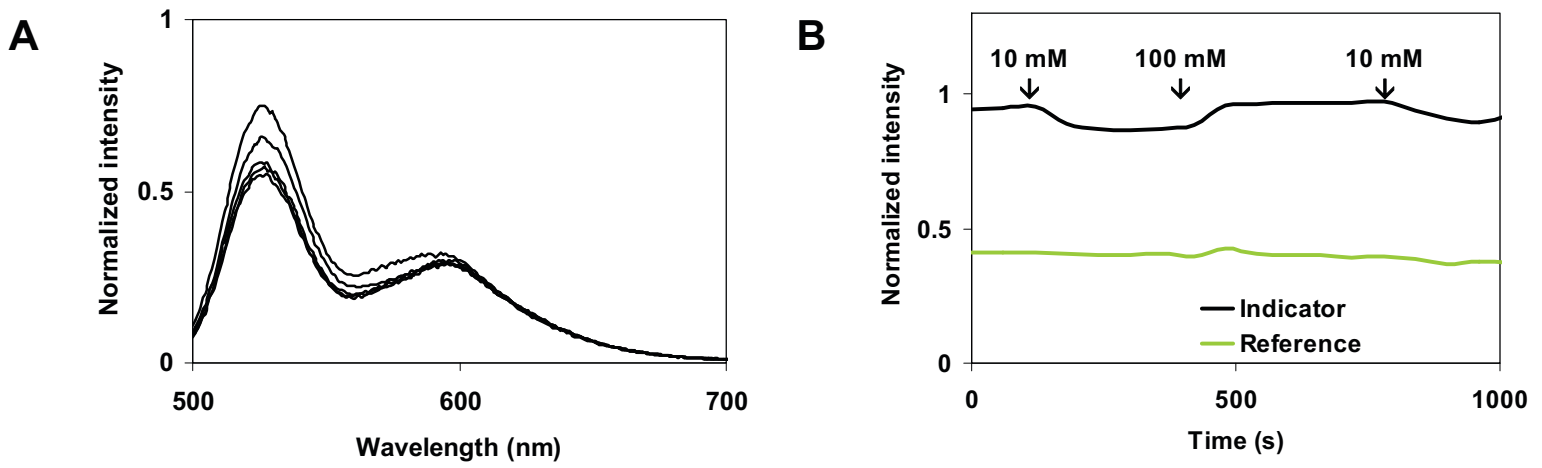

Figure 7. Properties of Gold nanosensors A) Fluorescence spectra of the SG - Texas Red linked nanoparticles suspended in HEPES $10 \mathrm{mM}$ at variable $\left[\mathrm{Na}^{+}\right]$(from top to bottom: 20,10,5,2, $0 \mathrm{mM} \mathrm{NaCl}$ complemented with $\mathrm{KCl}$ to attain a constant osmolarity of $290 \mathrm{mOsmol} / 1 ; \lambda_{\text {ex }}=488 \mathrm{~nm}$ ). B) Response to a change in $\left[\mathrm{Na}^{+}\right]$in a $\mathrm{CHO}$ cell as measured with nanosensors linked with SG and Texas Red. (Figure adapted from Stanca et al., Nanotechnology 21:55501 (2010)). 


\section{CONCLUSIONS}

In this study we assessed several ways to measure sodium concentrations with the non-ratiometric sodium indicator Sodium Green. Its fluorescence intensity depends on the sodium concentration (Fig. 3 B), and the relationship between sodium concentration and Sodium Green fluorescence (Fig. 3 C) can be exploited to measure sodium concentrations. However, in biological specimens fluorescence intensity measurements can be biased by inhomogeneities in the dye distribution, or a variation of the excitation light in space and time. Thus, there is no way to clearly attribute a change in the measured fluorescence intensity to a change of the sodium concentration.

One way to circumvent this problem is to measure fluorescence lifetimes, which are independent of the dye concentration or the excitation intensity. However, the fluorescence decay of Sodium Green is complex and cannot be explained by a simple model in which one lifetime component can be attributed to the sodium-free form of the dye, and another to the sodium-bound form (Fig. 4). Hence, the fluorescence decay cannot be fitted adequately by a biexponential function. A tri- or tetra-exponential fit would have to be used (Fig. 5, Table 1). In principle, the average lifetime $\left(\tau_{\mathrm{m}}\right)$ or the amplitudes $\left(\mathrm{A}_{1}, \mathrm{~A}_{3}\right)$ of the fast and slow lifetime component $\left(\tau_{1}, \tau_{3}\right)$ could still be used to estimate the sodium concentration, despite the lack of a good model. However, in practice these measurements are biased by interactions of the dye with intracellular components.

Another approach is to embed Sodium Green and a reference dye into a nanoparticle structure. In this study we used Texas Red as a reference dye. By taking into account the fluorescence signal of the reference dye, inhomogeneiteis in the dye concentration, or fluctuations in the light intensity, can be corrected for. Moreover, the nanoparticle structure does not only provide a scaffold for the indicator and the reference dye, it also ensures a defined microenvironment in which the fluorescence properties of the indicator are not compromised by interfering biomolecules.

\section{REFERENCES}

1 Hille, B. [Ion channels of excitable membranes], 3rd ed., Sinauer Associates, Sunderland (2001).

2 Hediger, M.A., Romero, M.F., Peng, J.B., Rolfs, A., Takanaga, H. and Bruford E.A., "The ABCs of solute carriers: physiological, pathological and therapeutic implications of human membrane transport proteins," Pflügers Arch. 447(5), 465-468 (2004).

3 Orlowski, J. and Grinstein, S., "Diversity of the mammalian sodium/proton exchanger SLC9 gene family," Pflügers Arch. 447(5), 549-565 (2004).

4 Soleimani, M. and Burnham, C.E., "The $\mathrm{Na}^{+} / \mathrm{HCO}_{3}{ }^{-}$cotransporters," J. Membr. Biol. 183(2), 71-84 (2001).

5 Philipson, K.D., Nicoll, D.A., Ottolia, M., Quednau, B.D., Reuter, H., John, S. and Qiu, Z, "The Na+/Ca2+ exchange molecule," Ann. N.Y. Acad. Sci. 976, 1-10 (2002).

6 Wright, E.M. and Turk, E, "The sodium/glucose cotransport family SLC5," Pflügers Arch. 447(5), 510-518 (2004).

7 Pieske, B., Houser, S.R., Hasenfuss, G. and Bers, D.M., "Sodium and the heart: a hidden key factor in cardiac regulation," Cardiovasc. Res. 57(4), 871-872 (2003).

8 Haugland, R.P. [Handbook of fluorescent probes and research products], $9^{\text {th }}$ ed., Molecular Probes, Eugene (2002).

9 Minta, A. and Tsien, R.Y., "Fluorescent indicators for cytosolic sodium," J. Biol. Chem. 264(32), 19449-19457 (1989).

10 Tsien, R.Y., "Fluorescent probes of cell signaling," Annu. Rev. Neurosci. 12, 227-253 (1989).

11 Harootunian, A.T., Kao, J.P.Y., Eckert, B.K. and Tsien R.Y., "Fluorescence ratio imaging of cytosolic free $\mathrm{Na}^{+}$in individual fibroblasts and lymphocytes," J. Biol. Chem. 264(32), 19458-19467 (1989).

12 Grynkiewicz, G., Poenie, M. and Tsien, R.Y., "A new generation of $\mathrm{Ca}^{2+}$ indicators with greatly improved fluorescence properties," J. Biol. Chem. 260(6), 3440-3450 (1985).

13 Nordlund, T.M., "Streak cameras for time-domain fluorescence," In: J.R. Lakowicz [Topics in Fluorescence Spectroscopy, Volume 1: Techniques], Plenum Press, New York, 183-260 (1991).

14 Biskup, C., Zimmer, T., Benndorf, K., "FRET between cardiac $\mathrm{Na}^{+}$channel subunits measured with a confocal microscope and a streak camera," Nat. Biotechnol. 22(2), 220-224 (2004).

15 Stanca, S.E., Nietzsche, S., Fritzsche, W., Cranfield, C., Biskup, C., "Intracellular ion monitoring using a gold-core polymer-shell nanosensor architecture," Nanotechnology (2010).

16 Szmacinski, H., Lakowicz, J.R., "Sodium Green as a potential probe for intracellular sodium imaging based on fluorescence lifetime," Anal Biochem 250(2), 131-138 (1997).

17 Despa, S., Vecer, J., Steels, P., Ameloot, M., "Fluorescence lifetime microscopy of the $\mathrm{Na}^{+}$indicator sodium green in HeLa cells, " Anal. Biochem. 281(2), 159-175 (2000). 


\title{
Multiphoton Microscopy in the Biomedical Sciences $X$
}

\author{
Ammasi Periasamy \\ Peter T. C. So \\ Karsten König \\ Editors
}

24-26 January 2010

San Francisco, California, United States

Sponsored by

SPIE

Cosponsored by

Becker \& Hickl GmbH (Germany)

Boston Electronics (United States)

Carl Zeiss Jena GmbH (Germany)

Chroma Technology (United States)

Coherent, Inc. (United States)

High Q Laser (US), Inc. (United States)

Horiba Jobin Yvon (United States)

JenLab GmbH (Germany)

Leica Microsystems (United States)

Newport-Spectra Physics (United States)

Olympus America (United States)

Omega Optical (United States)

Semrock, Inc. (United States)

Published by

SPIE

Volume 7569

Proceedings of SPIE, 1605-7422, v. 7569

SPIE is an international society advancing an interdisciplinary approach to the science and application of light. 
The papers included in this volume were part of the technical conference cited on the cover and title page. Papers were selected and subject to review by the editors and conference program committee. Some conference presentations may not be available for publication. The papers published in these proceedings reflect the work and thoughts of the authors and are published herein as submitted. The publisher is not responsible for the validity of the information or for any outcomes resulting from reliance thereon.

Please use the following format to cite material from this book:

Author(s), "Title of Paper," in Multiphoton Microscopy in the Biomedical Sciences X, edited by Ammasi Periasamy, Peter T. C. So, Karsten König, Proceedings of SPIE Vol. 7569 (SPIE, Bellingham, WA, 2010) Article CID Number.

ISSN 1605-7422

ISBN 9780819479655

Published by

SPIE

P.O. Box 10, Bellingham, Washington 98227-0010 USA

Telephone +1 3606763290 (Pacific Time) · Fax +1 3606471445

SPIE.org

Copyright (C) 2010, Society of Photo-Optical Instrumentation Engineers.

Copying of material in this book for internal or personal use, or for the internal or personal use of specific clients, beyond the fair use provisions granted by the U.S. Copyright Law is authorized by SPIE subject to payment of copying fees. The Transactional Reporting Service base fee for this volume is $\$ 18.00$ per article (or portion thereof), which should be paid directly to the Copyright Clearance Center (CCC), 222 Rosewood Drive, Danvers, MA 01923. Payment may also be made electronically through CCC Online at copyright.com. Other copying for republication, resale, advertising or promotion, or any form of systematic or multiple reproduction of any material in this book is prohibited except with permission in writing from the publisher. The CCC fee code is 1605 $7422 / 10 / \$ 18.00$.

Printed in the United States of America.

Publication of record for individual papers is online in the SPIE Digital Library.

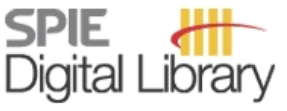

SPIEDigitallibrary.org

Paper Numbering: Proceedings of SPIE follow an e-First publication model, with papers published first online and then in print and on CD-ROM. Papers are published as they are submitted and meet publication criteria. A unique, consistent, permanent citation identifier (CID) number is assigned to each article at the time of the first publication. Utilization of CIDs allows articles to be fully citable as soon they are published online, and connects the same identifier to all online, print, and electronic versions of the publication. SPIE uses a six-digit CID article numbering system in which:

- The first four digits correspond to the SPIE volume number.

- The last two digits indicate publication order within the volume using a Base 36 numbering system employing both numerals and letters. These two-number sets start with $00,01,02,03,04$, 05, 06, 07, 08, 09, 0A, OB ... 0Z, followed by 10-1Z, 20-2Z, etc.

The CID number appears on each page of the manuscript. The complete citation is used on the first page, and an abbreviated version on subsequent pages. Numbers in the index correspond to the last two digits of the six-digit CID number. 


\section{Contents}

xi Conference Committee

KEYNOTE SESSION

756903 Plasmon-controlled fluorescence: applications to sensing and single molecule detection (Invited Paper) [7569-01]

Y. Fu, J. Zhang, J. R. Lakowicz, Univ. of Maryland School of Medicine (United States)

\section{RAMAN/CARS MICROSCOPY I}

756906 CARS and SHG microscopy of artificial bioengineered tissues (Invited Paper) [7569-05] A. Enejder, C. Brackmann, J.-O. Dahlberg, E. Vrana, P. Gatenholm, Chalmers Univ. of Technology (Sweden)

756908 High performance multimodal CARS microscopy using a single femtosecond source [7569-07]

A. F. Pegoraro, National Research Council Canada (Canada) and Queen's Univ. (Canada); A. D. Slepkov, A. Ridsdale, R. K. Lyn, D. J. Moffatt, J. P. Pezacki, National Research Council Canada (Canada); B. K. Thomas, L. Fu, L. Dong, M. E. Fermann, IMRA America, Inc. (United States); A. Stolow, National Research Council Canada (Canada) and Queen's Univ. (Canada)

756909 Frequency modulation coherent anti-Stokes Raman scattering (FM-CARS) microscopy based on spectral focusing of chirped laser pulses [7569-08]

B.-C. Chen, J. Sung, S.-H. Lim, The Univ. of Texas at Austin (United States)

\section{RAMAN/CARS MICROSCOPY II}

7569 OF Vibrational phase contrast CARS microscopy for quantitative analysis [7569-14]

M. Jurna, E. T. Garbacik, J. P. Korterik, C. Otto, J. L. Herek, H. L. Offerhaus, Univ. Twente (Netherlands)

\section{RAMAN/CARS MICROSCOPY III}

7569 ol Short-pulse fiber lasers for Raman microscopies (Invited Paper) [7569-17]

F. W. Wise, W. Renninger, S. Lefrancois, K. Kieu, M. Farrar, C. Schaffer, Cornell Univ. (United States); B. Saar, G. Holtom, S. Xie, Harvard Univ. (United States)

7569 0J A CARS solution with high temporal resolution [7569-18]

V. Lurquin, W. C. Hay, S. Landwehr, V. Krishnamachari, Leica Microsystems CMS GmbH (Germany) 
7569 OM Nonlinear Raman microscopy: improving detection through nonlinear optical interaction [7569-15]

G. I. Petrov, V. V. Yakovlev, Univ. of Wisconsin-Milwaukee (United States)

756900 Comparing coherent and spontaneous Raman scattering signals for biological imaging applications [7569-23]

B. R. Bachler, M. Cui, S. R. Nichols, J. P. Ogilvie, Univ. of Michigan (United States)

7569 OP Polarization-resolved coherent anti-Stokes Raman scattering microscopy [7569-96]

F. Munhoz, S. Brustlein, S. Brasselet, H. Rigneault, Institut Fresnel, CNRS, Aix-Marseille Univ. (France)

7569 OQ High-speed CARS spectral imaging using acousto optic tunable filter [7569-21]

M. Hashimoto, T. Minamikawa, T. Araki, Osaka Univ. (Japan)

\section{FLIM/FRET/FCS I}

7569 OS Better FLIM and FCS data by GaAsP hybrid detectors (Invited Paper) [7569-25]

W. Becker, B. Su, A. Bergmann, Becker \& Hickl GmbH (Germany)

7569 OU pH and chloride recordings in living cells using two-photon fluorescence lifetime imaging microscopy [7569-107]

M. Lahn, C. Hille, Univ. of Potsdam (Germany); F. Koberling, P. Kapusta, PicoQuant GmbH

(Germany); C. Dosche, Univ. of Potsdam (Germany)

7569 OW Regulatory assembly of the vacuolar proton pump $\mathrm{V}_{0} \mathrm{~V}_{1}$-ATPase in yeast cells by FLIM-FRET [7569-29]

S. Ernst, Univ. of Stuttgart (Germany); C. Batisse, EMBL Heidelberg (Germany); N. Zarrabi, Univ. of Stuttgart (Germany); B. Böttcher, EMBL Heidelberg (Germany) and Univ. of Edinburgh (United Kingdom); M. Börsch, Univ. of Stuttgart (Germany)

\section{FLIM/FRET/FCS II}

7569 OY Spectrally resolved fluorescence lifetime imaging: new developments and applications (Invited Paper) [7569-30]

A. Rueck, F. Dolp, ILM (Germany); B. v. Einem, C. A. F. v. Arnim, Univ. Ulm (Germany); D. Strat, ILM (Germany)

$7569 \mathrm{OZ}$ Comparison of FRET microscopy imaging techniques for studying protein-protein interactions in living cells using FRET standards [7569-27]

Y. Sun, S.-A. Seo, S. Provence, A. Periasamy, Univ. of Virginia (United States)

756913 In vivo stoichiometry monitoring of G protein coupled receptor oligomers using spectrally resolved two-photon microscopy [7569-34]

M. R. Stoneman, D. R. Singh, V. Raicu, Univ. of Wisconsin-Milwaukee (United States)

756914 New strategies to measure intracellular sodium concentrations [7569-35]

S. Dietrich, S. E. Stanca, C. G. Cranfield, B. Hoffmann, K. Benndorf, C. Biskup, Univ. Hospital

Jena (Germany) 
756915 Current developments in clinical multiphoton tomography (Invited Paper) [7569-36]

K. König, JenLab GmbH (Germany) and Saarland Univ. (Germany); M. Weinigel,

H. G. Breunig, A. Gregory, P. Fischer, M. Kellner-Höfer, R. Bückle, JenLab GmbH (Germany)

756916 Long-term marker-free multiphoton imaging, targeted transfection, optical cleaning of stem cell clusters, and optical transport of microRNA with extreme ultrashort laser pulses [7569-37]

A. Uchugonova, Univ. Saarland (Germany); Z. Földes-Papp, ISS, Inc. (United States) and Medizinische Univ. Graz (Austria); G. M. Kostner, Medizinische Univ. Graz (Austria); K. König, Univ. Saarland (United States) and JenLab GmbH (Germany)

756917 Arbitrary-scan imaging for two-photon microscopy [7569-38]

E. Botcherby, C. Smith, M. Booth, R. Juškaitis, T. Wilson, Univ. of Oxford (United Kingdom)

756918 Multiphoton microscopy as a diagnostic imaging modality for lung cancer [7569-39] I. Pavlova, K. R. Hume, S. A. Yazinski, R. M. Peters, R. S. Weiss, W. W. Webb, Cornell Univ. (United States)

756919 Controllable infrared continuum source for multiphoton imaging [7569-40]

C. de Mauro, D. Alfieri, Light4Tech Firenze s.r.l. (Italy); M. Arrigoni, D. Armstrong, Coherent, Inc. (United States); F. S. Pavone, Univ. of Florence (Italy)

7569 1D Two-photon imaging with $80 \mathrm{MHz}$ and 1-GHz repetition rate Ti:sapphire oscillators [7569-43] H. Studier, H. G. Breunig, JenLab GmbH (Germany); K. König, JenLab GmbH (Germany) and Saarland Univ. (Germany)

\section{SECOND HARMONIC GENERATION I}

756911 Adaptive multiphoton and harmonic generation microscopy for developmental biology [7569-48]

A. Thayil, A. Jesacher, T. Watanabe, T. Wilson, S. Srinivas, M. J. Booth, Univ. of Oxford (United Kingdom)

7569 1K Digital holography for second harmonic microscopy [7569-50]

E. Shaffer, C. Depeursinge, École Polytechnique Fédérale de Lausanne (Switzerland)

SECOND HARMONIC GENERATION II

7569 IP Second-order susceptibility imaging with polarization-resolved second harmonic generation microscopy [7569-54]

W.-L. Chen, T.-H. Li, P.-J. Su, C.-K. Chou, P. T. Fwu, National Taiwan Univ. (Taiwan); S.-J. Lin, National Taiwan Univ. Hospital (Taiwan); D. Kim, P. T. C. So, Massachusetts Institute of Technology (United States); C.-Y. Dong, National Taiwan Univ. (Taiwan)

$75691 \mathrm{Q}$ In vivo optical virtual biopsy of human oral cavity with harmonic generation microscopy [7569-55]

M.-R. Tsai, S.-Y. Chen, National Taiwan Univ. (Taiwan); D.-B. Shieh, National Cheng-Kung Univ. (Taiwan); P.-J. Lou, National Taiwan Univ. Hospital (Taiwan); C.-K. Sun, National Taiwan Univ. (Taiwan) and Academia Sinica (Taiwan) 
7569 IR Polarization and phase pulse shaping applied to nonlinear tensorial structure read-out [7569-56]

P. Schön, Institut Fresnel, CNRS, Aix-Marseille Univ. (France); M. Behrndt, Max Planck Institute of Molecular Cell Biology and Genetics (France); D. Aït-Belkacem, H. Rigneault, S. Brasselet, Institut Fresnel, CNRS, Aix-Marseille Univ. (France)

7569 is Nonlinear optical response of the collagen triple helix and second harmonic microscopy of collagen liquid crystals [7569-57]

A. Deniset-Besseau, Lab. d'Optique et Biosciences, Ecole Polytechnique, CNRS, INSERM (France); P. De Sa Peixoto, Lab. de Chimie de la Matière Condensée, CNRS, Univ. Paris 6 (France); J. Duboisset, C. Loison, Lab. de Spectroscopie Ionique et Moléculaire, CNRS, Univ. Claude Bernard Lyon I (France); F. Hache, Lab. d'Optique et Biosciences, Ecole Polytechnique, CNRS, INSERM (France); E. Benichou, P. Brevet, Lab. de Spectroscopie Ionique et Moléculaire, CNRS, Univ. Claude Bernard Lyon I (France); G. Mosser, Lab. de Chimie de la Matière Condensée, CNRS, Univ. Paris 6 (France); M. Schanne-Klein, Lab. d'Optique et Biosciences, Ecole Polytechnique, CNRS, INSERM (France)

$75691 \mathrm{U}$ Second harmonic generation in human ovarian neoplasias [7569-59]

L. Lamonier, F. Bottcher-Luiz, L. Pietro, L. A. L. A. Andrade, A. A. de Thomaz, C. L. Machado,

C. L. Cesar, Univ. Estadual de Campinas (Brazil)

\section{TECHNOLOGY DEVELOPMENT AND APPLICATIONS II}

$75691 \mathrm{~V}$ High-throughput three-dimensional (3D) lithographic microfabrication in biomedical applications [7569-60]

D. Kim, P. T. C. So, Massachusetts Institute of Technology (United States)

7569 IW Assessment of fibrotic liver disease with multimodal nonlinear optical microscopy [7569-61] F. LU, W. Zheng, National Univ. of Singapore (Singapore); D. C. S. Tai, Institute of Bioengineering and Nanotechnology (Singapore); J. Lin, National Univ. of Singapore (Singapore); H. Yu, Institute of Bioengineering and Nanotechnology (Singapore) and National Univ. of Singapore (Singapore); Z. Huang, National Univ. of Singapore (Singapore)

$756912 \quad$ Multimodal nonlinear microscopy at $1.5 \mu \mathrm{m}$ [7569-64]

C. Zhan, C. Joo, Q. Li, GE Global Research (United States); M. Y. Berezin, W. J. Akers, Y. Ye, S. Achilefu, Washington Univ. School of Medicine (United States); S. Yazdanfar, GE Global Research (United States)

756920 Multicolor excitation two-photon microscopy: in vivo imaging of cells and tissues [7569-76] D. Li, W. Zheng, J. Y. QU, Hong Kong Univ. of Science and Technology (Hong Kong, China)

756922 The analysis of fluorophore orientation by multiphoton fluorescence microscopy [7569-66] J. M. Leeder, D. L. Andrews, Univ. of East Anglia (United Kingdom)

756923 Two-photon microscopy with dynamic focusing objective using a liquid lens [7569-67] K.-S. Lee, P. Vanderwall, J. P. Rolland, The Institute of Optics, Univ. of Rochester (United States)

756926 Pulse shaping for reducing photodamage in multiphoton microscopy [7569-125]

D. Pestov, Y. Andegeko, V. V. Lozovoy, M. Dantus, Michigan State Univ. (United States) 
756927 Real-time molecular imaging of organelles in living cell by multifocus excitation CARS microscope [7569-70]

T. Minamikawa, T. Araki, M. Hashimoto, Osaka Univ. (Japan)

756928 In situ observation of collagen thermal denaturation by second harmonic generation microscopy [7569-71]

C.-S. Liao, Z.-Y. Zhuo, J.-Y. Yu, P.-H. G. Chao, S.-W. Chu, National Taiwan Univ. (Taiwan)

756929 Spatio-temporal control in multiphoton fluorescence laser-scanning microscopy (Best Poster Award) [7569-72]

A. K. De, D. Roy, D. Goswami, Indian Institute of Technology Kanpur (India)

7569 2A Discrimination of collagen in normal and pathological dermis through polarization second harmonic generation [7569-73]

P.-J. Su, W.-L. Chen, J.-B. Hong, T.-H. Li, R.-Jr Wu, C.-K. Chou, S.-J. Lin, C.-Y. Dong, National

Taiwan Univ. (Taiwan)

7569 2B Multispectral autofluorescence lifetime imaging of RPE cells using two-photon excitation [7569-74]

L. Zhao, D. Chen, J. Qi, J. Qu, Shenzhen Univ. (China)

7569 2C In vivo multiphoton imaging of obstructive cholestasis in mice [7569-75]

F.-C. Li, Y. Y. Lee, L.-L. Chiou, H.-S. Lee, C.-Y. Dong, National Taiwan Univ. (Taiwan)

7569 2D Versatile photonic crystal fiber-enabled source for multi-modality biophotonic imaging beyond conventional multiphoton microscopy [7569-77]

H. Tu, S. A. Boppart, Univ. of Illinois at Urbana-Champaign (United States)

$75692 \mathrm{~F} \quad$ Multiplex coherent anti-Stokes Raman scattering flow cytometry for real-time classification of particles in a microfluidic channel [7569-79]

C. H. Camp, Jr., S. Yegnanarayanan, A. A. Eftekhar, Georgia Institute of Technology (United States); H. Sridhar, Harvard Univ. (United States); A. Adibi, Georgia Institute of Technology (United States)

$75692 \mathrm{G}$ Quantitative analysis of biological tissues using Fourier transform-second-harmonic generation imaging [7569-80]

R. Ambekar Ramachandra Rao, M. R. Mehta, K. C. Toussaint, Jr., Univ. of Illinois Urbana-Champaign (United States)

$756921 \quad$ Fluorescence performance standards for confocal microscopy [7569-82]

S. Rüttinger, Physikalisch-Technische Bundesanstalt (Germany); P. Kapusta, V. Völlkopf,

F. Koberling, R. Erdmann, PicoQuant GmbH (Germany); R. Macdonald,

Physikalisch-Technische Bundesanstalt (Germany)

7569 2J Fiber-based multiphoton system [7569-83]

G. Liu, Beckman Laser Institute (United States) and Univ. of California, Irvine (United States); K. Kieu, F. W. Wise, Cornell Univ. (United States); Z. Chen, Beckman Laser Institute (United States) and Univ. of California, Irvine (United States) 
$75692 \mathrm{R} \quad$ In vivo deep tissue imaging with long wavelength multiphoton excitation (Best Poster Award) [7569-92]

D. Kobat, M. E. Durst, N. Nishimura, A. W. Wong, C. B. Schaffer, C. Xu, Cornell Univ. (United States)

$75692 \mathrm{~S}$ Coherent anti-Stokes Raman scattering microscopy using photonic crystal fibers [7569-93] M. Naji, S. Murugkar, K. R. Khan, H. Anis, Univ. of Ottawa (Canada)

$75692 \mathrm{~T} \quad$ High-resolution imaging of a corneal incision by second- and third-harmonic generation microscopy [7569-94]

L. Jay, Maisonneuve-Rosemont Hospital Research Ctr. (Canada), Univ. of Montreal (Canada), and Institut National de la Recherche Scientifique (Canada); C. Dion, Maisonneuve-Rosemont Hospital Research Ctr. (Canada) and Institut National de la Recherche Scientifique (Canada); A. Brocas, Lab. Laser, Plasmas et Procédés Photoniques (France); K. Singh, Maisonneuve-Rosemont Hospital Research Ctr. (Canada) and Institut National de la Recherche Scientifique (Canada); J.-C. Kieffer, Institut National de la Recherche Scientifique (Canada); I. Brunette, Maisonneuve-Rosemont Hospital Research Ctr. (Canada) and Univ. de Montréal (Canada); T. Ozaki, Maisonneuve-Rosemont Hospital Research Ctr. (Canada) and Institut National de la Recherche Scientifique (Canada)

7569 2V Broadband multiplex CARS microspectroscopy in the picosecond regime [7569-98] S. Michel, Institut Fresnel, CNRS, Aix-Marseille Univ. (France); A. Courjaud, Amplitude Systemes (France); J. Dudley, Institut FEMTO, CNRS (France); C. Finot, Institut Carnot de Bourgogne, CNRS, Univ. de Bourgogne (France); E. Mottay, Amplitude Systèmes (France); H. Rigneault, Institut Fresnel, CNRS, Aix-Marseille Univ. (France)

7569 2W Polarization second harmonic generation (PSHG) imaging of neurons: estimating the effective orientation of the SHG source in axons [7569-99]

S. Psilodimitrakopoulos, Institut de Ciències Fotòniques (Spain); V. Petegnief, G. Soria, Institut de Recerca Biomèdica de Barcelona (Spain); I. Amat-Roldan, Institut de Ciències Fotòniques (Spain); D. Artigas, Institut de Ciències Fotòniques (Spain) and Univ. Politècníca de Catalunya (Spain); A. M. Planas, Institut de Recerca Biomèdica de Barcelona (Spain); P. Loza-Alvarez, Institut de Ciències Fotòniques (Spain)

$75692 Y \quad$ Complementary equipment for controlling multiple laser beams on single scanner MPLSM systems [7569-101]

P. J. Helm, G. Nase, P. Heggelund, T. Reppen, Univ. of Oslo (Norway)

$75692 Z$ Investigating the protective properties of milk phospholipids against ultraviolet light exposure in a skin equivalent model [7569-102]

A. Russell, A. Laubscher, R. Jimenez-Flores, L. H. Laiho, California Polytechnic State Univ. (United States)

756930 In vivo tissue imaging using a compact mobile nonlinear microscope [7569-104] R. Cicchi, D. Kapsokalyvas, D. Stampouli, V. De Giorgi, D. Massi, T. Lotti, F. S. Pavone, Univ. degli Studi di Firenze (Italy) 
756931 Fast rasterscanning enables FLIM in macroscopic samples up to several centimeters [7569-106]

F. Koberling, V. Buschmann, PicoQuant GmbH (Germany); C. Hille, Univ. of Potsdam (Germany); M. Patting, PicoQuant GmbH (Germany); C. Dosche, Univ. of Potsdam (Germany); A. Sandberg, A. Wheelock, Karolinska Institutet (Sweden); R. Erdmann, PicoQuant GmbH (Germany)

756932 Extracellular oxygen concentration mapping with a confocal multiphoton laser scanning microscope and TCSPC card [7569-108]

N. A. Hosny, D. A. Lee, M. M. Knight, Queen Mary Univ. of London (United Kingdom)

756933 A multimodal multiphoton microscope for biological imaging [7569-109]

R. Mouras, A. Downes, G. Rischitor, M. Mari, A. Elfick, Univ. of Edinburgh (United Kingdom)

756937 Non-linear 3D microscopy of ex-vivo corneas [7569-113]

J. M. Bueno, E. J. Gualda, P. Artal, Univ. de Murcia (Spain)

756939 Annular aperture detection scheme in radially polarized coherent anti-Stokes Raman scattering (RP-CARS) microscopy for contrast improvement [7569-126]

J. Lin, F. LU, National Univ. of Singapore (Singapore); H. Wang, Data Storage Institute, A*STAR

(Singapore); W. Zheng, C. J. R. Sheppard, Z. Huang, National Univ. of Singapore (Singapore)

7569 3A Scheme for efficient fiber-based CARS probe [7569-130]

M. Balu, G. Liu, Beckman Laser Institute and Medical Clinic (United States); Z. Chen,

B. J. Tromberg, E. O. Potma, Beckman Laser Institute and Medical Clinic (United States) and Univ. of California, Irvine (United States)

Author Index 


\title{
Conference Committee
}

\author{
Symposium Chairs \\ James G. Fujimoto, Massachusetts Institute of Technology (United \\ States) \\ R. Rox Anderson, Wellman Center for Photomedicine, Massachusetts \\ General Hospital (United States), and Harvard School of Medicine \\ (United States)
}

Program Track Chairs

Ammasi Periasamy, University of Virginia (United States)

Daniel L. Farkas, Cedars-Sinai Medical Center (United States)

Conference Chairs

Ammasi Periasamy, University of Virginia (United States)

Peter T. C. So, Massachusetts Institute of Technology (United States)

Karsten König, Saarland Universität (Germany)

\section{Program Committee}

Wolfgang Becker, Becker \& Hickl GmbH (Germany)

Keith M. Berland, Emory University (United States)

Guy C. Cox, The University of Sydney (Australia)

Alberto Diaspro, Università degli Studi di Genova (Italy)

Chen-Yuan Dong, National Taiwan University (Taiwan)

Dennis Donley, Olympus America (United States)

Kevin W. Eliceiri, University of Wisconsin, Madison (United States)

Scott E. Fraser, California Institute of Technology (United States)

Paul M. French, Imperial College London (United Kingdom)

Hans C. Gerritsen, Utrecht Universiteit (Netherlands)

Min Gu, Swinburne University of Technology (Australia)

Stefan W. Hell, Max-Planck-Institut für biophysikalische Chemie (Germany)

Brian A. Herman, The University of Texas Health Science Center at San Antonio (United States)

Satoshi Kawata, Osaka University (Japan)

Arnd K. Krueger, Newport Spectra-Physics (United States)

Joseph R. Lakowicz, University of Maryland School of Medicine (United States)

Stephen M. McDonald, Coherent, Inc. (United States)

Simon C. Watkins, University of Pittsburgh (United States)

Paul W. Wiseman, McGill University (Canada) 
Sunney X. Xie, Harvard University (United States)

Bernhard Zimmermann, Carl Zeiss Jena GmbH (Germany)

Warren R. Zipfel, Cornell University (United States)

Session Chairs

Keynote Session

Ammasi Periasamy, University of Virginia (United States)

1 Raman/CARS Microscopy I

Sunney X. Xie, Harvard University (United States)

2 Raman/CARS Microscopy II

Ji-Xin Cheng, Purdue University (United States)

3 Raman/CARS Microscopy III

Hervé Rigneault, Institut Fresnel (France)

4 FLIM/FRET/FCS I

Angelika C. Rueck, Universität Ulm (Germany)

5 FLIM/FRET/FCS II

Hans C. Gerritsen, Utrecht Universiteit (Netherlands)

6 Technology Development and Applications I

Peter T. C. So, Massachusetts Institute of Technology (United States)

7 Second Harmonic Generation I

Chen-Yuan Dong, National Taiwan University (Taiwan)

8 Second Harmonic Generation II

Paul J. Campagnola, University of Connecticut Health Center (United States)

9 Technology Development and Applications II

Karsten König, JenLab GmbH (Germany)

Poster Session

Vladimir Ghukasyan, National Yang-Ming University (Taiwan)

Eric O. Potma, University of California, Irvine (United States)

Kevin W. Eliceiri, University of Wisconsin-Madison (United States) 